\title{
Measuring the spatial integration of the China-born population in Australia, 1981-2016
}

\author{
Qing Guan' ${ }^{1}$
}

Published online: 24 September 2019

(c) Springer Nature B.V. 2019

\begin{abstract}
The China-born population have a long history of migrating to and settling in Australia, and have recently grown to become the third largest overseas-born population. To measure their integration in Australia, a spatial perspective is adopted in this paper. Spatial distribution is an important indicator of immigrants' integration in the host country and is linked to their socioeconomic integration. It is generally agreed that the more concentrated immigrants distribute, the less integrated socioeconomically they are; the more immigrants' spatial distribution patterns mirror the local population, the more integrated they are. Distributions of mainland Chinese population at sub-national levels are examined. Using coefficient of variation and index of dissimilarity, spatial integration patterns of the China-born population in Australia are analyzed over time, across age groups and immigrant cohorts, and against those of other birthplace groups using 1981-2016 Australian census data. Changes in the distribution of China-born immigrants substantiate the 'contrasting' dispersion-concentration picture uncovered in earlier Australian censuses. With the influx of international students and skilled migrants, results from spatial integration analyses show a slow but uninterrupted improvement in the China-born immigrants' spatial integration after the 2001 Census. In the spatial analysis across immigrant cohorts, it is found that the interaction between cohort characteristics and lengths of residence in Australia is likely an important factor influencing the spatial distribution patterns of mainland Chinese. Findings of the study contribute to the knowledge of immigrants' spatial distribution and integration in the host country, especially in the context of Australia and a context of broader Chinese diaspora in major immigration countries.
\end{abstract}

Keywords Mainland Chinese migrants · Australia $\cdot$ Spatial integration · Index of dissimilarity $\cdot$ Coefficient of variation

Qing Guan

qing.guan@anu.edu.au

1 School of Demography, ANU College of Arts and Social Sciences, The Australian National University, 9 Fellows Road, Acton, ACT 2601, Australia 


\section{Introduction}

Studies on immigrants' integration are becoming numerous and multifaceted on the global migration research agenda (Wingens et al. 2011; Castles et al. 2014; National Academies of Sciences, Engineering, and Medicine (NASEM) 2015). For Australia, multiculturalism and cultural diversity became important on its research and policy agendas since the dismantlement of discriminatory 'White Australia' policies in the 1970s (Ziguras 2012; Chiou 2017). With immigrants from mainland China forming the largest non-European-origin population in Australia since the 2006 Census, however, there are only a few studies on Chinese's integration in the post-'White Australia' era and fewer addressed the spatial dimension of their integration (Johnston et al. 2001; Ang 2014; Coughlan 2008a, b).

This paper examines how levels of spatial integration for the China-born population in Australia changed using aggregated data from 1981 to 2016 Australian Censuses. The China-born population have a long history of migrating to and settling in Australia and have recently grown to become the third largest overseasborn population following United Kingdom-born and New Zealand-born populations. A spatial perspective is adopted to analyse their integration because the distribution of immigrants is closely linked to many other aspects of their integration in the host country. Spatial integration is seen as 'a product of increasing cultural and economic integration' of immigrants (NASEM 2015: p. 209). There are many dimensions of spatial integration measurement (Massey and Denton 1988). It is widely recognized that the more concentrated immigrants distribute, the less integrated socioeconomically they are; the more immigrants' spatial distribution patterns mirror the local population (i.e. low spatial separation), the higher socioeconomic integration they achieved (Lo and Wang 1997; Musterd 2003; NASEM 2015). Of the many measurement options (Massey and Denton 1988; Rogers and Raymer 1998; Bell et al. 2002; Lichter et al. 2015), Coefficient of Variation and Index of Dissimilarity are used in this paper to measure spatial concentration and spatial evenness - two essential aspects of immigrants' spatial integration. Distribution patterns of mainland Chinese immigrants are analysed and visualized to set the tone.

This paper makes a significant contribution to the body of literature on immigrants' integration in Australia by examining 35 years of census statistics of the China-born immigrants on various scales. A study using Australian data would also add evidence to the spatial integration literature in the world's major receiving countries and a state with a good welfare system. Results of the study contribute to the body of literature on the age, immigrant cohort, and temporal effects on immigrants' integration in the receiving country.

The rest of the paper is structured as follows. In "Background" section, some background is provided on the China-born population in Australia, followed by discussions on spatial integration literature and measurements. The third section describes two sets of census data and spatial analysis methods used in this paper. The fourth section examines the over-time population structures, distributions, 
and immigrant cohort compositions of the China-born population in Australia. Results from spatial integration analyses are presented in the fifth section to examine the levels of China-born immigrants' spatial integration over time, between birthplace groups, across age groups, and across immigrant cohorts. The last section concludes the paper with discussions on the findings and implications.

\section{Background}

\section{The China-born population in Australia}

The Chinese have a long history of migrating to and settling in Australia (Choi 1975). Those born in mainland China have become the third largest overseas-born population since the 2006 Census. In the 2016 Census, the number of China-born immigrants reached over half a million, accounting for $2 \%$ of Australia's total population and $8 \%$ of the overseas-born population.

A series of significant events have affected immigration levels and immigrants' compositions from mainland China to Australia since the 1970s (see Appendix Table 3). The dismantlement of Australia's discriminatory immigration policies in the mid-1970s set the beginning of increasing numbers of long-term immigrants from Asia. The rapid development of mainland China's economy enabled Chinese students to embark on self-funded education in Western countries since the 1980s. The 1989 Tiananmen Incident resulted in large intakes of students from mainland China as humanitarian migrants in early 1990s (Birrell 1994; Shu and Hawthorne 1996; Jupp 2001; Hugo 2008; Coughlan 2008b; Aozhou Ju Liu Er Shi Zhou Nian Ji Nian Wei Yuan Hui (Aozhou) 2014). A series of innovative immigration policies were introduced from 1998 onwards to retain temporary migrants (international students in particular) as permanent migrants in Australia (Chiou 2017; Tang et al. 2014 cited in Wang et al. 2018). Such chronologies can also be found for Chinese in Canada, the United States and other major immigration countries (Lo and Wang 1997; Ewing 2012).

Spatial distribution of the China-born population, in particular their urban-rural distribution and state level disparities, has been of great importance in the Australian Chinese literature (Huck 1968; Inglis 1972; Choi 1975; Kee and Huck 1991; Ho and Coughlan 1997; Coughlan 2008a, b; Reeves and Mountford 2011; Wang et al. 2018). Australia has a 'highly concentrated settlement system' (Bell et al. 2018: p 150), with more than two-thirds of its population living in a capital city (ABS 2016b). The majority of Chinese people also live in cities, with Sydney being the main settlement area (Ho and Coughlan 1997; Coughlan 2008a, b; Wang et al. 2018). With very few exceptions (Coughlan 2008a, b; Edgar 2012; Wang et al. 2018), however, it remains unclear how spatial integration levels of the China-born immigrants varied on different scales and dimensions. In particular, immigrant cohort (and the length of residence in Australia) is a less studied dimension in Australia's spatial analysis literature (exceptions are Hugo and Harris 2011; Coughlan 2008b). Using 2006 Australian Census data and a dichotomized cohort variable, Coughlan (2008b) found that those who arrived in Australia after 1991 were less 
concentrated at Statistical Local Area level. With new waves of immigrants coming to Australia as international students and skilled migrants, further investigations on the cohort and duration-of-stay effects are needed. To fill these gaps, this paper examines the spatial distribution and levels of integration of the China-born population in Australia across age groups, across immigrant cohorts, against those of other birthplace groups, and over time.

\section{Spatial integration of immigrants and the measurement}

Spatial distribution is an important indicator of immigrants' integration in the host country. It is associated with residential and neighbourhood composition, socioeconomic status and mobility, housing affordability, economic participation, crossethnic friendships, and intermarriage (Newman 1985; NASEM 2015; Wessel et al. 2017). A cross-national review suggests that 'some degree of residential segregation is to be found in many immigration countries' (Castles et al. 2014, p. 274). It is widely recognized that the more concentrated immigrants distribute and the less similar their distribution compared to the local population, the more segregated they are (Lo and Wang 1997; Musterd 2003; NASEM 2015). Exceptions are for some welfare states where immigrants are less needed to endeavour upward spatial mobility for social and spatial equality (Musterd 2003; Wessel et al. 2017), and some ethnic enclaves that facilitate (new) immigrants' education, cultural and language practices, employment, adaptation to the host community, and availability of social services (Portes and Manning 1994). In Australia, a trend towards greater evenness in the spatial economy has been identified by Bell et al. (2018) in understanding a systematic decline in internal migration intensities. Its implication on the spatial distribution and integration of immigrants remains less clear.

The integration/segregation patterns of immigrants can be in different forms. It has been observed recently for immigrants in the United States that on the one hand, international migrants re-migrated across the United States, a lot to the remote areas, becoming more spatially dispersed; on the other hand, there is a tendency of immigrants becoming more focused spatially in certain major receiving areas (NASEM 2015, chapter 5). For the Chinese immigrants in Australia, Coughlan (2008a, b) used Statistical Local Area level ${ }^{1}$ data from 1986 to 2006 Censuses and uncovered a similar contrasting picture that Chinese immigrants became increasingly dispersed into the broader Australian community, while 'a few areas of "high" Chinese spatial concentration have developed since 1986' (Coughlan 2008b, p. 161). In a recent study on mainland Chinese's spatial distribution in Australia's metropolitan areas, Wang et al. (2018) also found consistent patterns that the Chinese were decentralized from traditional settlement suburbs but concentrated in both traditional and new settlement areas. The coexistence of increasing dispersion and increasing concentration,

\footnotetext{
1 Statistical Local Area is from the old geographic standard (Australian Standard Geographical Classification) and is of similar geographic scale as Statistical Area Level 2 used in this paper (from Australian Statistical Geography Standard). The two geographic scales are not entirely equivalent. For instance, in 2011 census where data on both geographic standards were reported, there were 1390 Statistical Local Areas and 2214 Statistical Area Level 2 areas (ABS 2010, 2011b).
} 
however, not necessarily associates with a lower level of integration. For instance, the influx of immigrants to many of the United States' largest cities was associate with 'accelerated white flight to the suburbs and beyond' (Lichter et al. 2015: p. 844), and 'the optimism associated with recent declines in racial segregation in U.S. metropolitan areas may be dampened by new evidence of racial and ethnic geographic balkanization at other levels of geography' (Lichter et al. 2015: p. 843).

To better examine the levels of immigrants' spatial integration, measurements need to be chosen with care (NASEM 2015, chapter 5). Do migrants' levels of spatial integration depend on whether they became diffused or concentrated across geographic areas over time, the composition of their neighbourhoods, or the spatial evenness between migrants and non-migrants? In this paper, a decomposition of neighbourhood population by immigrant cohort and two spatial integration measurements are used to examine the concentration, local population composition and evenness of the China-born population in Australia.

Widely used spatial integration measurements include the Index of Dissimilarity (also known as the Segregation Index), the Coefficient of Variation, the Gini Index, and the Theil Index (Massey and Denton 1988; Lo and Wang 1997; Rogers and Raymer 1998; Musterd 2003; Edgar 2012). There are some discussions on which index to rely on, but no universal best agreement is reached (see discussions in Massey and Denton 1988; Rogers and Raymer 1998). Massey and Denton (1988) grouped 17 indices into five dimensions of spatial integration measurement, including the Index of Dissimilarity which is the simplest, readily interpretable, and the most widely used measurement of spatial (un)evenness. Rogers and Raymer (1998) compared five indices in measuring the spatial focus of internal migration flows and argued that the Coefficient of Variation index being computationally simpler and more accurately, capturing "the "common sense" interpretation of geographical concentration' (Bell et al. 2002, p. 66). Because of their computational simplicity and straightforward interpretation, Coefficient of Variation and Index of Dissimilarity are used in this paper to measure the evenness and concentration of the China-born population's spatial integration/segregation in Australia. Advantages and limitations of these two indices are further discussed in "Measuring spatial integration" section.

\section{Data and methods}

\section{The cross-tabulated census data}

Two sets of data are sourced from the Australian Bureau of Statistics (ABS). The first one is Australian Census TableBuilder with population data tabulated by birthplace, age, sex, year of arrival, and geographic level for 2011 and 2016 Censuses. Statistical Area Level 2 (SA2), which represents 'a community that interacts together socially and economically' (ABS 2016a), is used to capture spatial patterns on small geographic scales. ${ }^{2}$ SA2 level data are only available for the 2011 and 2016

\footnotetext{
${ }^{2}$ SA2 areas can be large in inland areas. Map 1 presents the sizes of SA2 areas across Australia.
} 
Censuses. There are 2214 SA2 areas in 2011, of which 2193 represent usual residents in the eight major states or territories. Other Territory, Offshore Migratory Category, and No Usual Address are excluded for the analysis. Similarly, in 2016, 2288 out of 2310 SA2 areas are used.

The second set of data represents Australian census population by birthplace, age and sex from 1981 to 2016. The tables were requested from ABS at the Statistical Division (SD) level between 1981 and 2011 and at Statistical Area Level 3 (SA3) in 2016 as part of a larger project funded by the Australian Reserach Council (DP150104405). SD represents "relatively homogeneous geographic regions characterised by identifiable social and economic links between the inhabitants and between the economic units within the region, under the unifying influence of one or more major towns or cities" (ABS 2001b). A drawback in the data is that the SD boundaries have changed at each census. ${ }^{3}$ To make over-time comparisons meaningful, SDs are adjusted and transformed to 47 Harmonized Statistical Divisions (HSD areas) based on intercensal boundary changes and capital-regional distinctions ${ }^{4}$ for 1981-2011. The 2016 HSD areas are aggregated from SA3 areas to obtain consistent and comparable geography. ${ }^{5}$ HSD geography captures both the capital-regional distribution and state level disparities. However, the boundary change effects and aggregation effects are not fully removed on the HSD scale, which should be borne in mind when interpreting the results. A map and a table of the 47 consistent HSD areas are presented in Appendix Map 2 and Table 4.

The China-born immigrants are defined as persons reporting mainland China as the birthplace in Australian censuses. Therefore, immigrants born in Hong Kong, Macau and Taiwan are not counted in the China-born population but as part of the other Northeast Asia-born population.

\section{Measuring spatial integration}

To understand the distribution of mainland Chinese immigrants, census population sizes and shares are analysed over time on national and sub-national levels in "Distribution of the China-born population". Age compositions are examined at national and sub-national levels. The 2016 SA2 level China-born population sizes are mapped to visualize sub-national population distribution. The China-born population are decomposed by five-year interval immigrant cohort to identify the composition of same-origin neighbourhoods at SA2 level.

\footnotetext{
3 SD boundary changes were more frequent than five-year intercensal period. ABS recorded a series of yearly and/or intercensal SD changes in catalogue 1216.0 from 1994 onwards (http://www.abs.gov.au/ AUSSTATS/abs@.nsf/DetailsPage/1216.01994?OpenDocument) and in catalogue 2101.0 (was 2905.0) for 1991 Census (http://www.ausstats.abs.gov.au/ausstats/free.nsf/0/D534B1B9BB0583F1CA2574BF0 00049CC/\$File/29050_1991_250_Census_Geographic_Areas.pdf).

4 For the method of harmonizing geographic areas over time, see Guan (2018).

5 Documents available on request.
} 
In "Spatial integration of the China-born population in Australia" section, the Coefficient of Variation is used to quantify the level of spatial concentration on HSD and SA2 levels. The index is calculated as a ratio of standard deviation of the Chinaborn population sizes across all sub-national areas to the mean of it. Higher values of the Coefficient of Variation index represent higher levels of spatial inequality, but there are 'no logical limits' (Bell et al. 2002: p. 457).

The Index of Dissimilarity compares two populations directly. It is used to quantify inter-group spatial separation (or evenness as in Massey and Denton (1988)). The Index of Dissimilarity has been widely used in spatial population studies (Lo and Wang 1997; Rogers and Raymer 1998; Edgar 2012; Hugo 2011). It describes the percentage of a population that would have to change place of residence to have the same distribution as that of another population (Hugo 2011). The index for the China-born and the Australia-born populations at HSD level is calculated as:

$$
\text { Index of Dissimilarity }=\frac{1}{2} \sum_{i=1}^{n}\left|\frac{c h n_{i}}{C H N}-\frac{a u s_{i}}{A U S}\right|
$$

where $c h n_{i}$ is the China-born population size of the $i$ th HSD, aus $s_{i}$ is the Australiaborn population size of the $i$ th $\mathrm{HSD}, \mathrm{CHN}$ is the total China-born population size at national level, and $A U S$ is the total Australia-born population size at national level. $\frac{c h n_{i}}{C H N}-\frac{a u s_{i}}{A U S}$ is the spatial distributions' proportional difference between the Chinaborn and the Australia-born in area $i$. If the index equals 0, it means the two populations have exactly the same distribution. If the index is 1 , it means no person of one population is living in the same area as the other population (Hugo 2011).

Because of their simple computations and straightforward interpretations, the Coefficient of Variation and Index of Dissimilarity are used together to evaluate the spatial integration of immigrants born in mainland China. Using them together addresses two key dimensions of spatial integration: the concentration and the evenness (Massey and Denton 1988; Rogers and Raymer 1998; Bell et al. 2002). There are, however, some limitations in the two indices. Most critically, Index of Dissimilarity does not control for the principle of transfers in its definition: only when transfers of the China-born population from areas where they are overrepresented (above the country's China-born proportion) to areas where they are underrepresented (below the country's China-born proportion) will affect the value of the index (Winship 1978; Massey and Denton 1988; Rogers and Raymer 1998; Reardon and O'Sullivan 2004). However, many studies have substantiated a strong correlation between the Index of Dissimilarity and other segregation measurements which do not violate the principle of transfers, including the Theil index and Gini index (White 1983; Massey and Denton 1988: Tables 3-5; Rogers and Raymer 1998: Table 1).

Due to the mathematical nature of the two indices, some cautions need to be taken when comparing values calculated on HSD and SA2 levels, and at SA2 level in 2011 and 2016. There are slightly different numbers of SA2 areas in the two censuses (ABS 2016a) and the two years' indices therefore are not directly comparable. Readers also need to be careful when interpreting indices calculated for areas with small population sizes, because ABS randomly assigned numbers to counts that are less 
(a) China-born

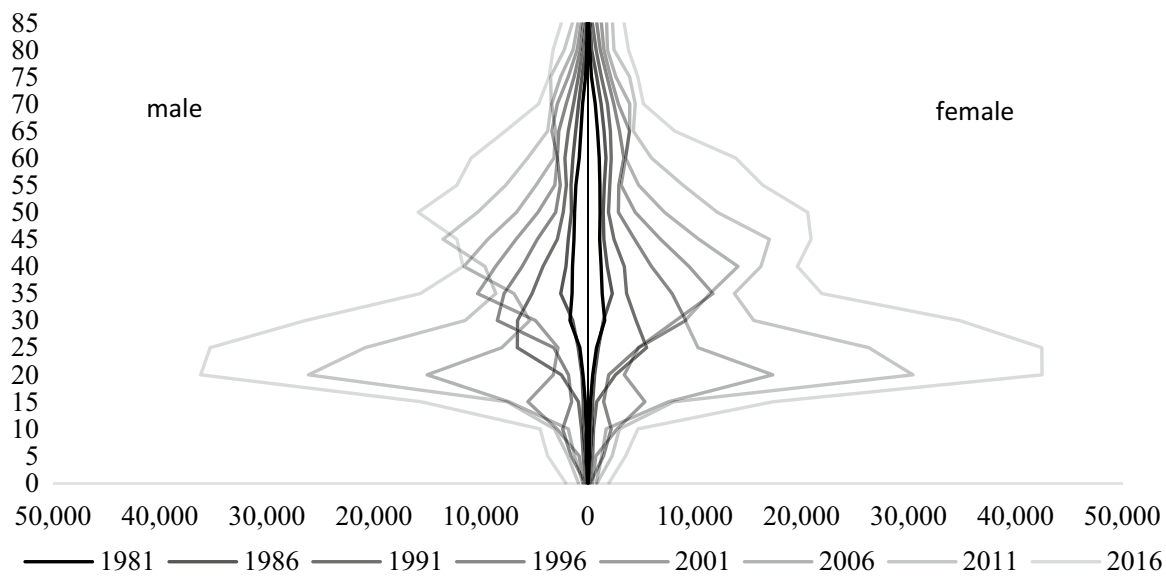

(b) Australia-born

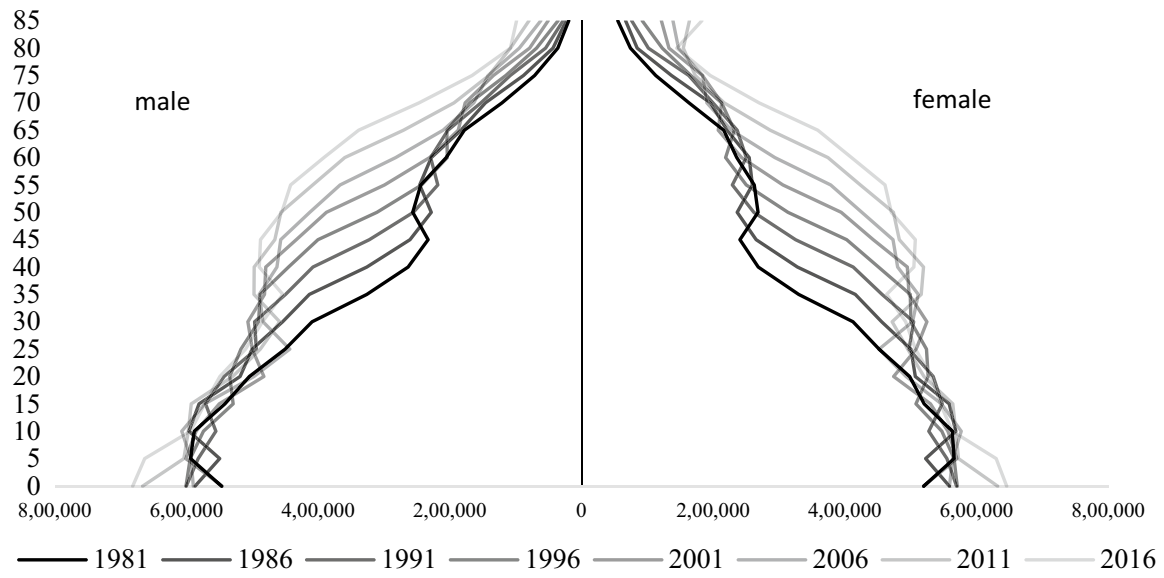

Fig. 1 Population pyramids of the China-born (a) and the Australia-born (b) in Australia: 1981-2016 census year population (ABS 1981, 1986, 1991, 1996, 2001a, 2006, 2011a, 2016b)

than 10 to control for confidentiality purposes. The random number issue, however, is possibly ruled out if consistent patterns are observed from multiple years and scales.

\section{Distribution of the China-born population}

\section{National level distribution across age groups and immigrant cohorts}

At the national level, the China-born population has become the largest non-European-origin immigrant population in Australia since the 2006 Census. Population 
Table 1 The China-born population in Australia census, by period of first arrival in Australia: 2011 and 2016 (ABS 2011a, 2016b)

\begin{tabular}{|c|c|c|c|c|c|c|}
\hline \multirow{2}{*}{$\begin{array}{l}\text { Period of first } \\
\text { arrival in Aus- } \\
\text { tralia }\end{array}$} & \multicolumn{3}{|l|}{2011 Census } & \multicolumn{3}{|l|}{2016 Census } \\
\hline & $\begin{array}{l}\text { Length of } \\
\text { residence in } \\
\text { Australia }\end{array}$ & Size & Share $(\%)$ & $\begin{array}{l}\text { Length of } \\
\text { residence in } \\
\text { Australia }\end{array}$ & Size & Share $(\%)$ \\
\hline Before 1971 & $40+$ & 8704 & 2.73 & $45+$ & 7588 & 1.49 \\
\hline 1972-1976 & $35-39$ & 2641 & 0.83 & $40-44$ & 2396 & 0.47 \\
\hline 1977-1981 & $30-34$ & 4557 & 1.43 & $35-39$ & 4231 & 0.83 \\
\hline 1982-1986 & $25-29$ & 8386 & 2.63 & $30-34$ & 8194 & 1.61 \\
\hline 1987-1991 & $20-24$ & 42,081 & 13.19 & $25-29$ & 42,553 & 8.35 \\
\hline 1992-1996 & $15-19$ & 26,855 & 8.42 & $20-24$ & 26,666 & 5.23 \\
\hline 1997-2001 & $10-14$ & 38,189 & 11.97 & $15-19$ & 40,238 & 7.90 \\
\hline 2002-2006 & $5-9$ & 66,055 & 20.71 & $10-14$ & 69,843 & 13.71 \\
\hline 2007-2011 & $0-4$ & $107,358^{*}$ & 33.66 & $5-9$ & 116,175 & 22.80 \\
\hline 2012-2016 & & & & $0-4$ & $168,849 * *$ & 33.14 \\
\hline Not stated & Not stated & 14,141 & 4.43 & Not stated & 22,811 & 4.48 \\
\hline Total & & 318,967 & & & 509,544 & \\
\hline
\end{tabular}

*Arrived between 1 Jan 2011 and 9 August 2011

**Arrived between 1 Jan 2016 and 9 August 2016

pyramids of the China-born population are presented in Fig. 1a against that of the Australia-born population in Fig. 1b for census years between 1981 and 2016. During this time, the China-born population grew by a factor of 20 , increasing from 26,068 persons in 1981 to 509,562 persons in 2016. The age structure also changed substantially in relation to the Australia-born population.

The 2016 China-born population pyramid has two bulges: one between age 20 and 29, the other between age 45 and 54. The first bulge is age-related, resulting from substantial population growth among people aged in their 20s, since the 2001 Census. Increases in these young age groups are predominantly driven by intakes of international students. Conversely, the second bulge is primarily cohort-based. It largely comprises Tiananmen Incident-related student migrants who came to Australia in the late 1980s and early 1990s when they were aged in their late 20s and early 30 s.

Immigrant cohort sizes of the China-born population are further examined in Table 1 for the 2011 and 2016 Censuses. The two census-year populations are decomposed into five-year interval immigrant cohorts, from those who arrived before 1971 to those who arrived less than five years before the census. The corresponding lengths of residence in Australia and cohort sizes and shares in 2011 and 2016 Censuses are presented for each immigrant cohort in Table 1.

Those who arrived in Australia within five years before the census form the largest immigrant cohort. These newest arrivals comprised one third of the China-born population. The second largest immigrant cohort is the next recent arrivals who have been in Australia for 5-9 years. Recent arrivals accounted for one fifth of the 
China-born immigrant population in 2011 and 2016. Arrivals between 1987 and 1991 form the third largest immigrant cohort, accounting for $13 \%$ of 2011 Chinaborn population and $8 \%$ of 2016 China-born population. They are those who arrived in Australia before or immediately after the Tiananmen Incident. Before the dismantlement of discriminatory immigration policies (mid-1970s), there were around ten thousand mainland Chinese persons in the population.

\section{Sub-national decompositions}

The $47 \mathrm{HSD}$ areas are aggregated to 15 capital and regional areas to examine the changing distribution of the mainland Chinese population between 1981 and 2016 (Table 2). Each state or territory is divided into a capital city area and a regional area, except for the Australian Capital Territory (ACT), which does not have any non-capital HSD. The three bottom rows in Table 2 summarise sizes and shares of the China-born population in all capital city areas, all non-capital areas, and total Australia, respectively.

Among all 15 areas, Sydney had the largest number of China-born population between 1981 and 2016 (Table 2). Though the number of mainland Chinese living in Sydney almost tripled between 2001 and 2016, the proportion of mainland Chinese living in Sydney declined in post-2001 period. They became more dispersed across the eight capital cities. Significant increases in both the number and the share were observed in Melbourne. Other capital city areas also saw substantial growth of their China-born population. Darwin and Hobart had the smallest number and share among all eight capital cities (Table 2). Their small shares are partly due to the total population sizes of these two capital cities being relatively small. However, shares of the China-born immigrants in local populations were also substantially lower in these two capital cities: $1 \%$ of Darwin's and $0.9 \%$ of Hobart's population were born in mainland China in 2016, compared to $2 \%$ in the national population. Of all eight capital city areas, Sydney (5\%), Melbourne (4\%) and ACT (Canberra, 3\%) had relatively higher shares of China-born residents compared to the national level in the 2016 Census.

Of all non-capital areas, the Rest of New South Wale (NSW) had the largest China-born population group, but with a decreasing proportion of mainland Chinese living there (dropped from $6 \%$ in 1981 to $2 \%$ in 2016 as presented in Table 2). Other non-capital regions all experienced increases in the absolute size of China-born residents, except for the Rest of South Australia (SA) in 1991-1996, Rest of Western Australia (WA) in 1986-1991 and 1996-2001, and Rest of Northern Territory (NT) in 1991-2001.

As presented in the bottom lines of Table 2, the number of mainland Chinese residing in capital city areas increased drastically from 22,295 in 1981 to 488,457 in 2016. Those living in non-capital areas also increased substantially from 2571 in 1981 to 20,289 in 2016. The share of non-capital areas declined from $10 \%$ in 1981 to $4 \%$ in 2016 , whilst the share of capital city areas increased from $90 \%$ in 1981 to $96 \%$ in 2016 . However, the non-capital share uninterruptedly increased between 2001 and 2011 Censuses. Concurrent with the dispersion of China-born population 


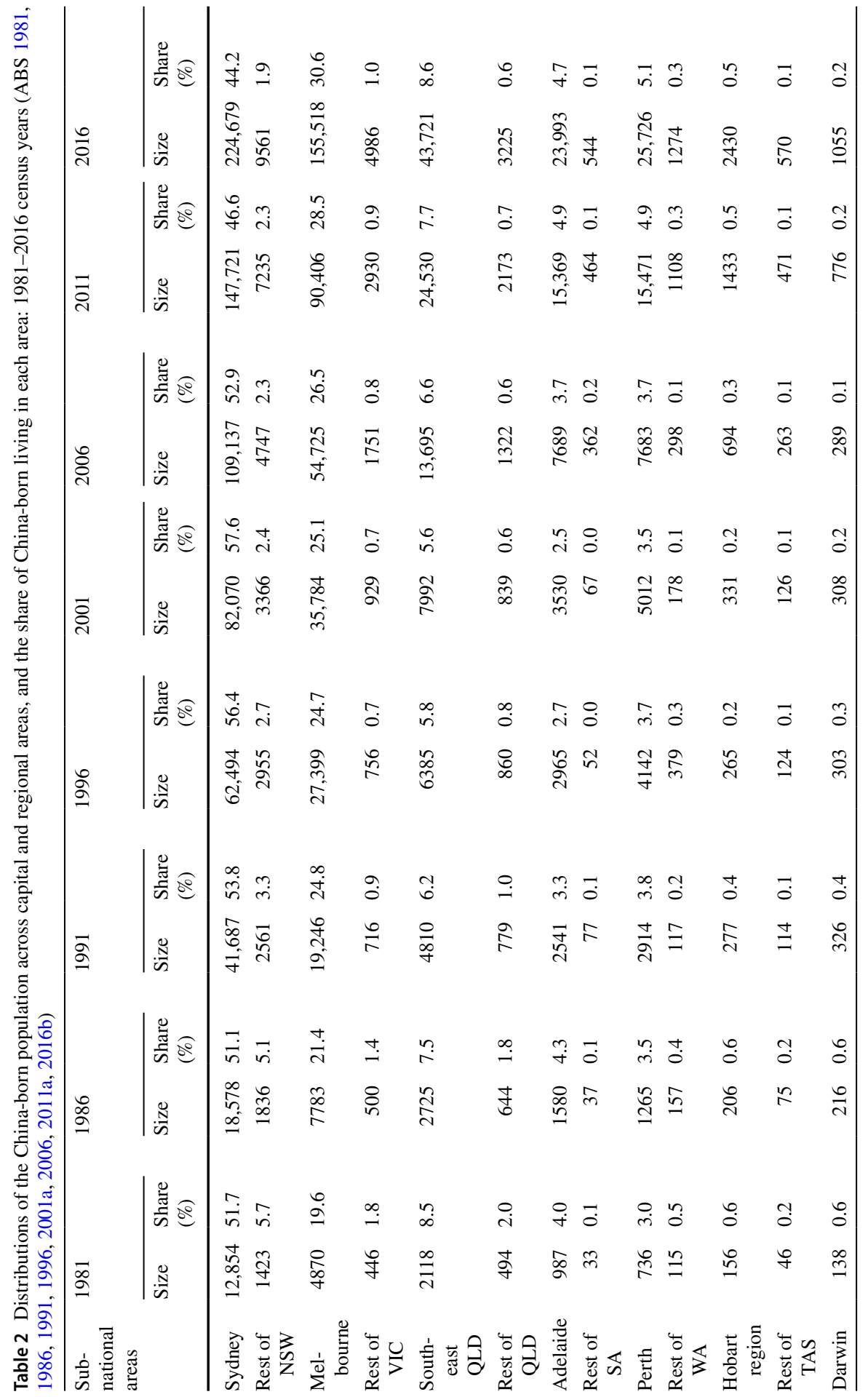




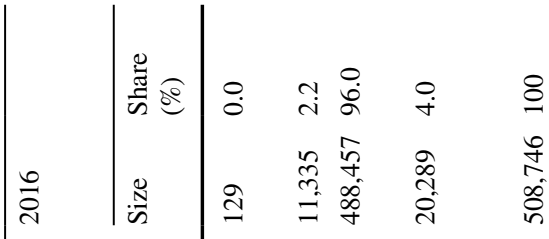

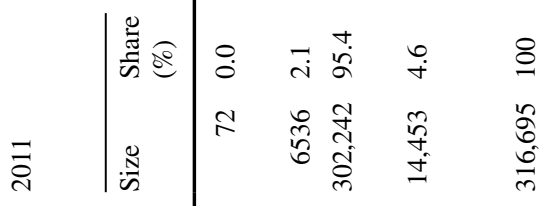

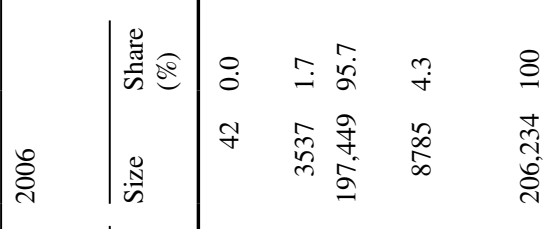

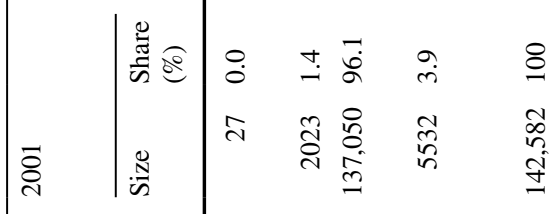

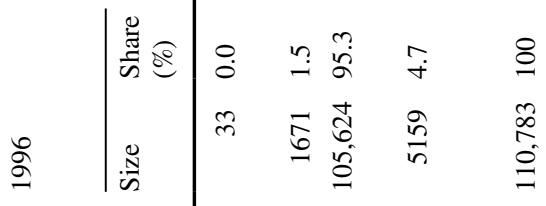

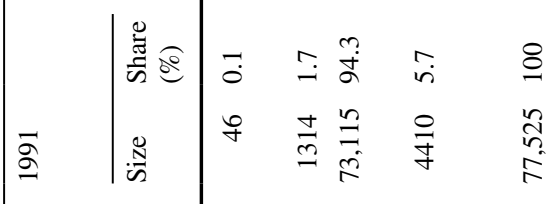

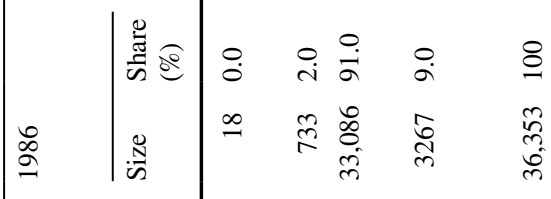

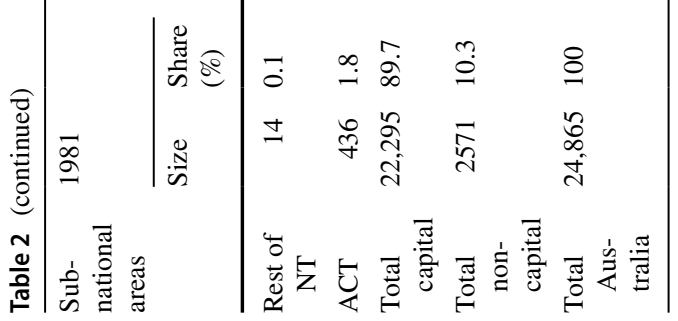




\section{Group A: Established settlement areas}

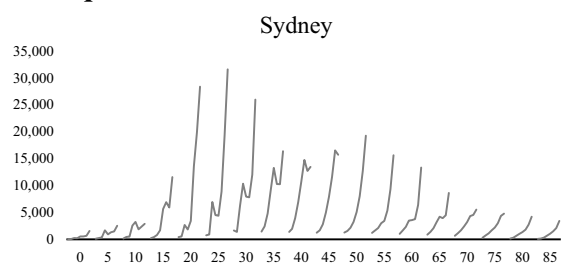

\section{Group B: Emerging settlement areas}
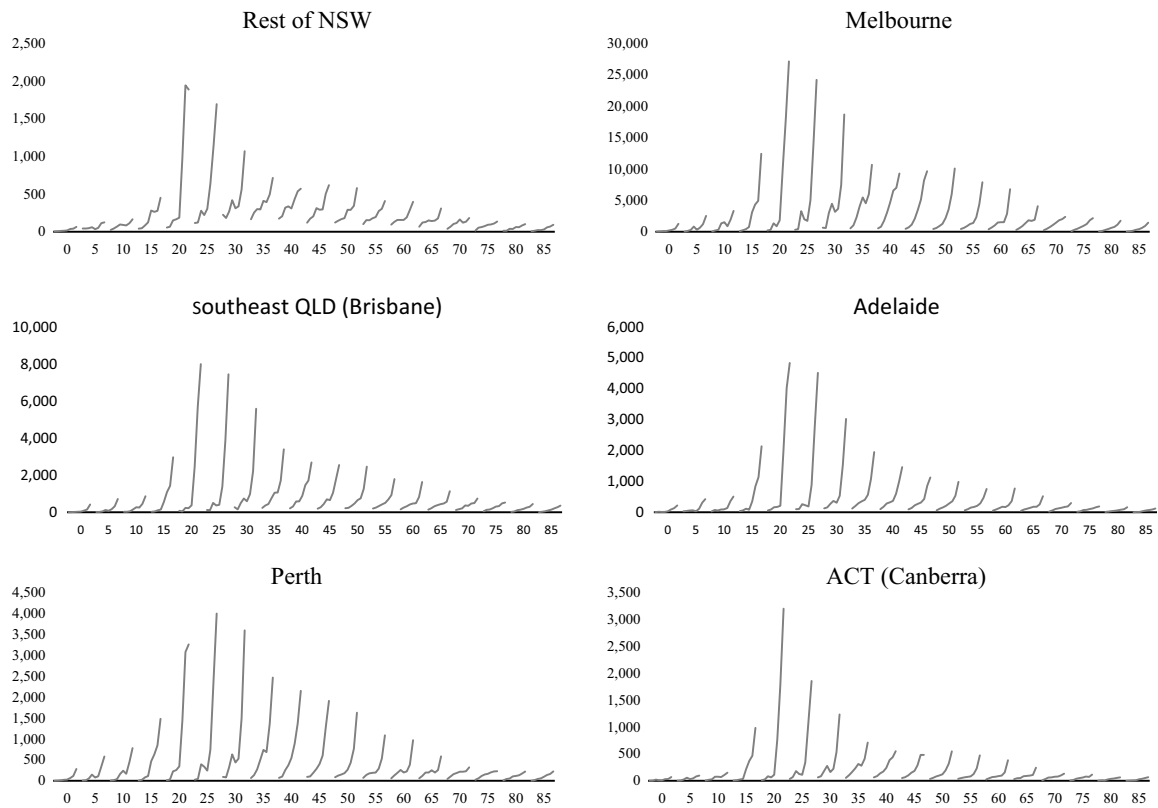

Fig. 2 Changes of age-specific census year China-born population sizes: by age group (horizontal axis) (ABS 1981, 1986, 1991, 1996, 2001a, 2006, 2011a, 2016b). Note:each age-specific line comprises eight census data points, with its very left end denoting 1981 census data and its very right end denoting 2016 census data

across the eight capital cities in the post-2001 period, they became increasingly dispersed to regional Australia and then more concentrated in capital city areas (Melbourne and Brisbane in particular).

Changes in the China-born population's sub-national age structures are presented in Fig. 2. Each area is represented by an age-specific line chart. Each age-specific line represents population size changes between 1981 (the very left end of each line) and 2016 (the very right end of each line). The 15 areas are clustered to three groups.

With minor inter-group differences, the China-born immigrants have young age structures in all capital and non-capital areas. Sydney is the only area in Group A. It represents an established Chinese settlement area with substantial numbers (and 


\section{Group C: Other areas}
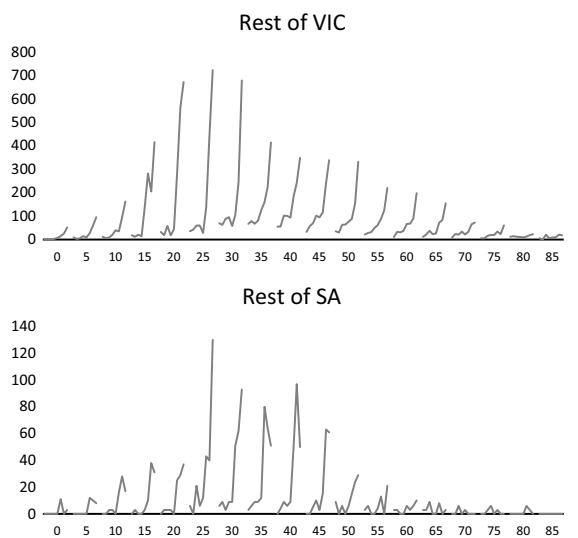

Hobart

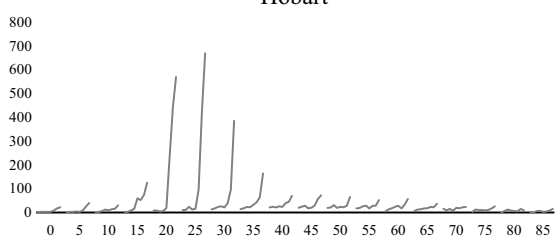

Darwin

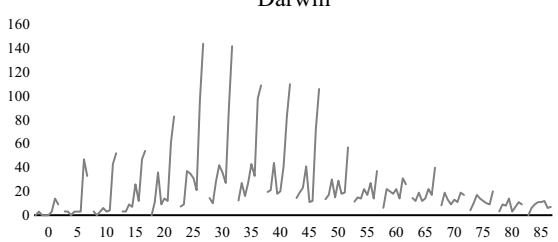

Rest of QLD

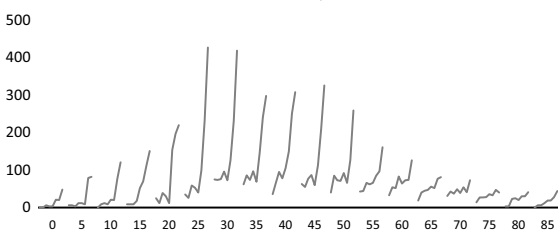

Rest of WA

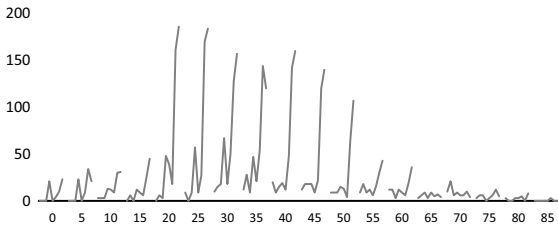

Rest of TAS

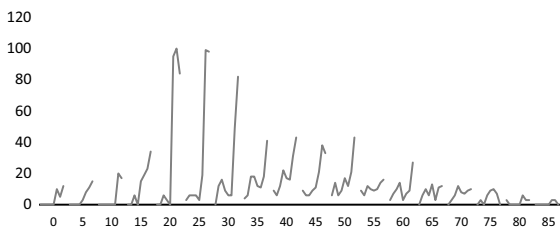

Rest of NT

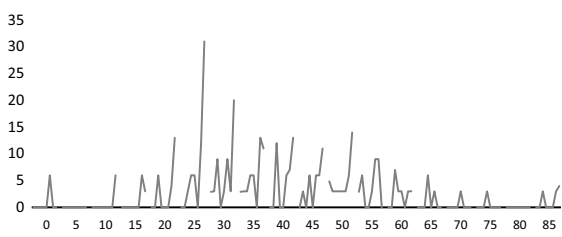

Fig. 2 (continued)

high proportions) of mature age China-born residents. Compared to the other two groups, Sydney experienced population growth much earlier with substantial growth in 35-60 age groups. The largest age group in Sydney is 25-29 years old observed in 2016 (31,575 persons). Group B are emerging settlement areas, consisting of Rest of NSW, Melbourne, Southeast Queensland (QLD, Brisbane region), Adelaide, Perth, and ACT (Canberra). Compared to Sydney, these emerging settlement areas experienced population growth more recently and have younger populations. Most of the growth was observed in post-2001 years. The largest age group in Group B is 20-24 years old observed in 2016 in Melbourne (27,116 persons). Group C includes Rest of Victoria (VIC), Rest of QLD, Rest of SA, Rest of WA, Hobart, Rest of Tasmania (TAS), Darwin, and Rest of NT. Areas in Group C have much less China-born residents and are usually seen as regional or remote areas. The largest age group in Group C is 25-29 years old observed in 2016 in the Rest of VIC (723 persons). 


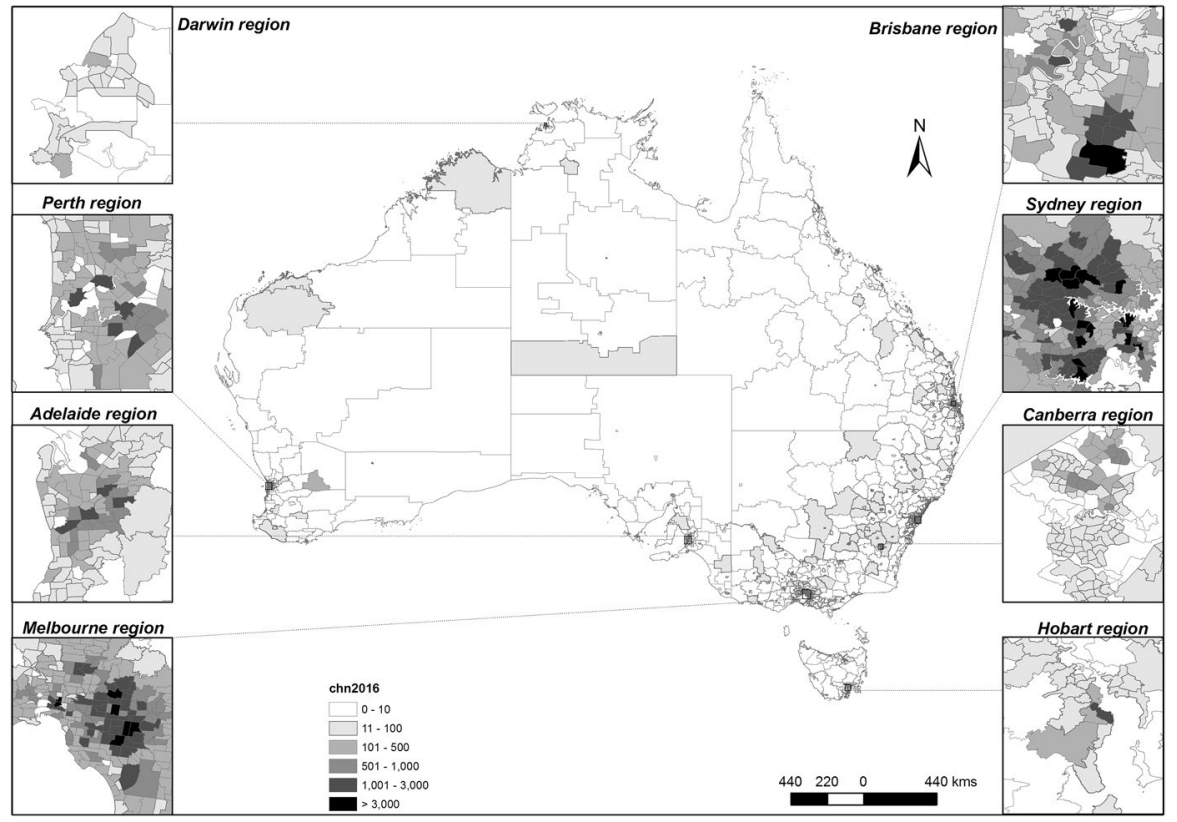

Map 1 Distribution of the China-born population across Australia on Statistical Area level 2, 2016 (ABS 2016b)

Distribution of the China-born population at the time of the 2016 Census is mapped at SA2 level in Map 1. Areas with a significantly large China-born population (>3000 persons) are coloured dark black. Numbers of such major settlement SA2 areas increased from ten in the 2011 Census to 23 in the 2016 Census. The ten major settlement SA2 areas in 2011 are all in Sydney, accounting for $48 \%$ of Sydney's total China-born population. Of the 23 major settlement SA2 areas in the 2016 Census, 15 are in Sydney (accounted for 33\% of Sydney's total China-born population), seven are in Melbourne (accounted for 21\% of Melbourne's total China-born population), and one is in Brisbane (accounted for 9\% of Brisbane region's total China-born population). All together they account for $22 \%$ of Australia's Chinaborn population in 2016. Of the 23 areas, Melbourne CBD had the largest number of China-born residents (9286 persons), followed by Hurstville in Sydney (8187 persons). The 23 SA2 areas cluster within capital regions, and all of them are surrounded by or neighboured to SA2 areas with more than 1000 China-born residents (coloured the second darkest in Map 1). Such geographic pattern reflects the clustering feature described by Massey and Denton (1988).

In 2016, only one SA2 could be considered as a mainland Chinese enclave according to the 30\% threshold (Burnley 1992, cited in Dunn 1998): $35 \%$ of Hurstville's residents are born in mainland China. It was followed by Burwood-Croydon (27\%), Melbourne (SA2) and Clayton (25\%), and Kingsford (24\%). Using 30\% as the threshold, none of the ten 2011 large SA2 areas can be regarded as an enclave 


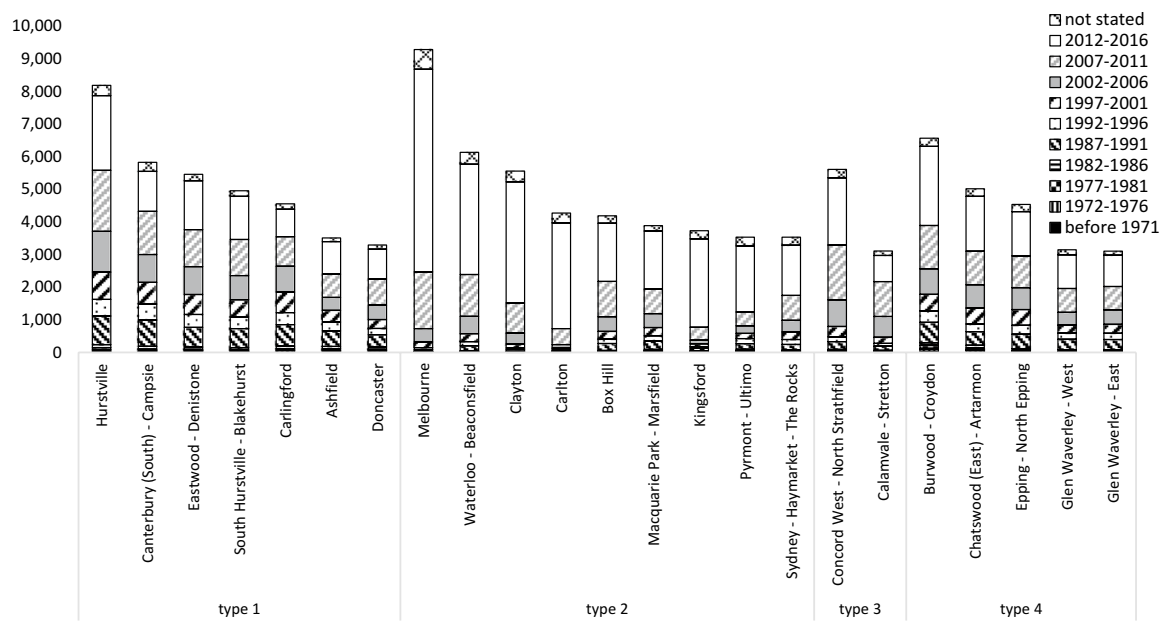

Fig. 3 Decomposition of the local area population by period of arrival: SA2s with more than 3000 China-born usual residents in 2016 census (ABS 2016b)

for mainland Chinese. The highest share in 2011 Census was observed in Hurstville, with $24 \%$ of its residents born in mainland China.

The 2016 China-born population living in major settlement SA2 areas are further decomposed by immigrant cohort (defined using period of first arrival in Australia). As presented in Fig. 3, each stacked bar denotes the size of China-born residents in a SA2 area and consists of 10 five-year interval immigrant cohorts and a 'not stated' group. Further grouping the 10 intervals into before-2002, 2002-2011, and after2011 periods of arrival, the SA2 areas could be categorized into four types of major settlement areas characterized by the composition of immigrant cohorts. ${ }^{6}$

The first type is established settlement local areas, where relatively high proportions of their China-born residents migrated to Australia in early years. One such SA2 area is in Melbourne (Doncaster) and six others are in Sydney, predominantly areas with well-known concentrations of Chinese persons (Hurstville, Canterbury (South)_Campsie, Eastwood_Denistone, South Hurstville-Blakehurst, Carlingford, and Ashfield). Of the seven established settlement SA2 areas, 31 to $42 \%$ of their China-born residents first arrived in Australia before 2002. On average, 26\% of their China-born residents first arrived after 2011. Benchmarked to the 2016 national level composition, $27 \%$ of the China-born immigrants first arrived in Australia before 2002, 38\% first arrived between 2002 and 2011, and 35\% first arrived after 2011 (Table 1).

The second type is emerging residential areas where substantially high proportions of their China-born residents arrived in Australia very recently. Of the nine such SA2 areas, 45 to $82 \%$ of their China-born residents first arrived in Australia

\footnotetext{
6 Those who did not state a SA2 as their usual residence at census night are excluded from the calculation of proportions.
} 


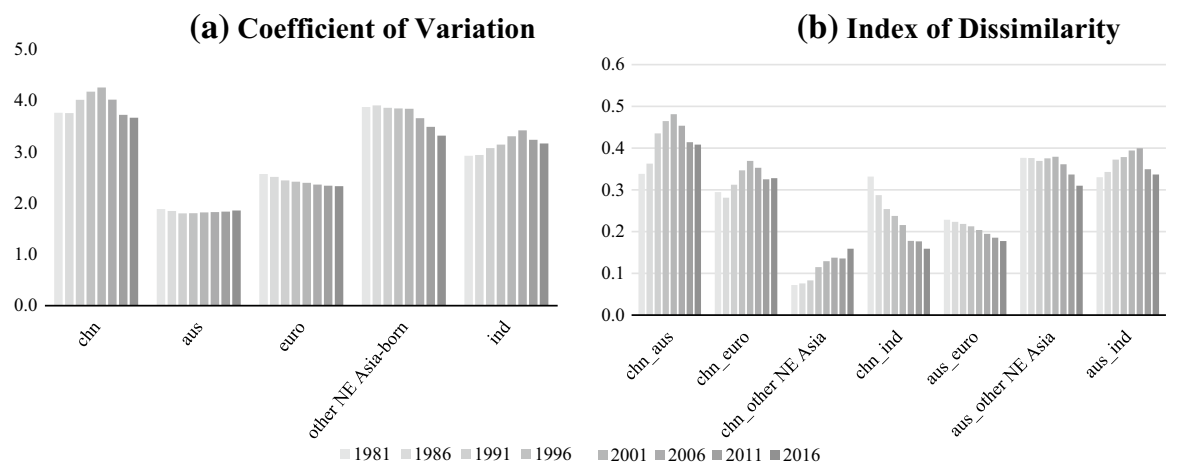

Fig. 4 Spatial concentration of the China-born and other non-Chinese birthplace groups over time: HSD level Coefficient of Variation (a) and Index of Dissimilarity (b) (ABS 1981, 1986, 1991, 1996, 2001a, 2006, 2011a, 2016b). Note: chn: China-born, aus: Australia-born, euro: Europe-born, other NE Asian: non-Chinese North East Asian, ind: India-born

between 2012 and 2016. All of the nine SA2s have more than $79 \%$ of their Chinaborn residents who first arrived in Australia after 2001. SA2s with more than $70 \%$ of their China-born residents who arrived in Australia after 2011 are areas encompassing or neighbouring university campuses (i.e. Kingsford and University of New South Wales, Carlton and Monash University, Clayton and University of Melbourne, and Melbourne SA2 area and Royal Melbourne Institute of Technology). The growth of mainland Chinese residents in these SA2s reflects the increasing numbers of Chinese international students in Australian universities. In particular, the number of China-born residents in Melbourne SA2 area increased from 2804 in 2011 Census to 9286 in 2016 Census, with $72 \%$ of its mainland Chinese residents first arriving in Australia after 2011.

The third type of major settlement SA2 areas have the majority of their Chinaborn residents who first arrived in Australia between 2002 and 2011, with less who arrived before 2002. Concord West-North Strathfield in Sydney and CalamvaleStretton in Brisbane are the two SA2s of this type. On average, 52\% of their Chinaborn residents first arrived in Australia between 2002 and 2011, and 15\% before 2002. The remaining five SA2 areas consist of the fourth type. All five areas have relatively balanced immigrant cohort composition in 2016. Each has approximately one third of their China-born residents who first arrived in Australia before 2002, one third arrived between 2002 and 2011, and one third after 2011. Three of the SA2 areas are in Sydney (Burwood-Croydon, Chatswood (East)_Artarmon, and Epping-North Epping), and two are in Melbourne (Glen Waverley-West, and Glen Waverley-East).

Among all the capital cities, Sydney and Melbourne are primary settlement zones with both established and emerging residential areas. Characteristics and compositions of the first two types of major SA2 settlement areas align with Wang et al. (2018) who found that the China-born became increasingly concentrated in areas of earlier Chinese settlement and areas with educational resources. 


\section{Spatial integration of the China-born population in Australia}

\section{Over time and compared to other birthplaces}

Spatial integration of the China-born population is compared against another four birthplace groups. Figure $4 \mathrm{a}$ presents the Coefficient of Variation index of Chinaborn, Australia-born, Europe-born, other Northeast Asia-born, and India-born populations at HSD level in 1981-2016 Censuses. The Coefficient of Variation measures the level of spatial concentration and is calculated as a ratio of standard deviation of the population sizes across all HSD areas to the mean of it (see "Measuring spatial integration" section). Each birthplace in Fig. 4a has eight bars representing the index from 1981 (the very left bars) to 2016 (the very right bars).

As shown in Fig. 4a, the China-born population became increasingly concentrated at HSD level in the 1980s and 1990s, reaching the highest level of spatial concentration in 2001 (Coefficient of Variation=4.26). Subsequently, the Chinaborn became more dispersed in post-2001 Censuses. Compared to persons born in Australia and Europe, persons born in mainland China were distributed much less equally across the 47 HSD areas. Levels of concentration were relatively similar between the China-born, the India-born and other Northeast Asia-born migrants.

Figure $4 \mathrm{~b}$ presents the Index of Dissimilarity between seven pairs of populations at HSD level between 1981 and 2016. The Index of Dissimilarity compares the level of spatial unevenness by summing up the sub-national distribution differences of each pair of populations (see "Measuring spatial integration" section). Each pair of populations in Fig. 4b has eight bars representing the Index of Dissimilarity between 1981 (the very left bars) and 2016 (the very right bars).

Spatial separation between the China-born and the Australia-born populations was substantially high at HSD level (Fig. 4b). The Index of Dissimilarity between the two populations was higher than 0.3 in all eight census years, indicating substantial separation between them (according to thresholds described in Hugo 2011; Edgar 2012). The index between the China-born and the Australia-born populations has been the highest amongst all pairs of comparisons in the last six censuses. After 2001, the level of their separation gradually declined, indicating an increasing level of spatial integration for the China-born population over the last two decades.

The HSD level separation between persons born in mainland China and persons born in other Northeast Asian countries was much lower $(<0.2)$. However, the index gradually increased from 0.07 in 1981 to 0.16 in 2016, indicating increasing levels of distributional dissimilarities between the two. Conversely, the index between persons born in mainland China and persons born in India gradually decreased from 0.33 in 1981 (highly separated) to 0.16 in 2016 (little separation). The convergence of the Chinese and Indian distribution patterns is particularly clear after 2001 Census when Australia started to see large inflows of international students and skilled migrants from both China and India. 


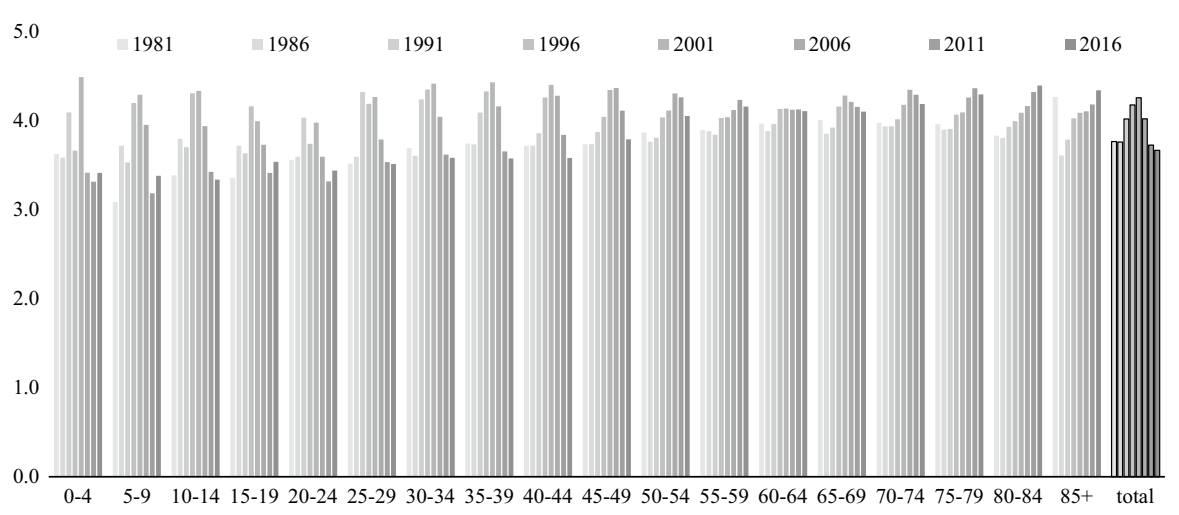

Fig. 5 Coefficient of Variation across age groups (horizontal axis) and over time: The China-born population, HSD level (ABS 1981, 1986, 1991, 1996, 2001a, 2006, 2011a, 2016b)

\section{Across age groups and over time}

To examine age effects on the China-born population's spatial concentration, the Coefficient of Variation is calculated for 18 abridged age groups at HSD level using data from the 1981-2016 Censuses. Results are presented in Fig. 5. Each age group has eight grouped bars representing census years Coefficient of Variation indices from 1981 (left) to 2016 (right). The indices calculated for age-aggregated Chinaborn populations are presented on the right end as a comparison.

As presented in Fig. 5, all age-specific Coefficient of Variations indices are higher than 3 between 1981 and 2016, indicating high levels of concentration among all age groups. However, temporal changes of spatial concentration varied across age groups. Between 1981 and 2001, almost all age groups had experienced increasing levels of spatial concentration. After 2001, the levels of spatial concentration declined for children, young adults, and mature age adults, but further increased for those who aged 55 and above.

To examine age effects on the China-born population's spatial evenness, the Index of Dissimilarity is calculated between the China-born immigrants who were aged 20-24 and four other birthplace groups, and between the China-born immigrants who were aged 45-49 and four other birthplace groups (Fig. 6). The two age groups are compared to examine spatial integration differences between young adults and mature age Chinese.

Spatial separation was found to be stronger between the 45-49 years old Chinese and three non-Northeast Asian populations. Young Chinese were relatively less separated from the Australia-born population, particularly in post-2001 years. Also, in the post-2001 period, the levels of spatial separation substantially reduced between young Chinese and the India-born population, but not so much between mature age Chinese and the India-born population. For persons born in other Northeast Asian countries, young Chinese were relatively more separated from them, compared to mature age Chinese. 


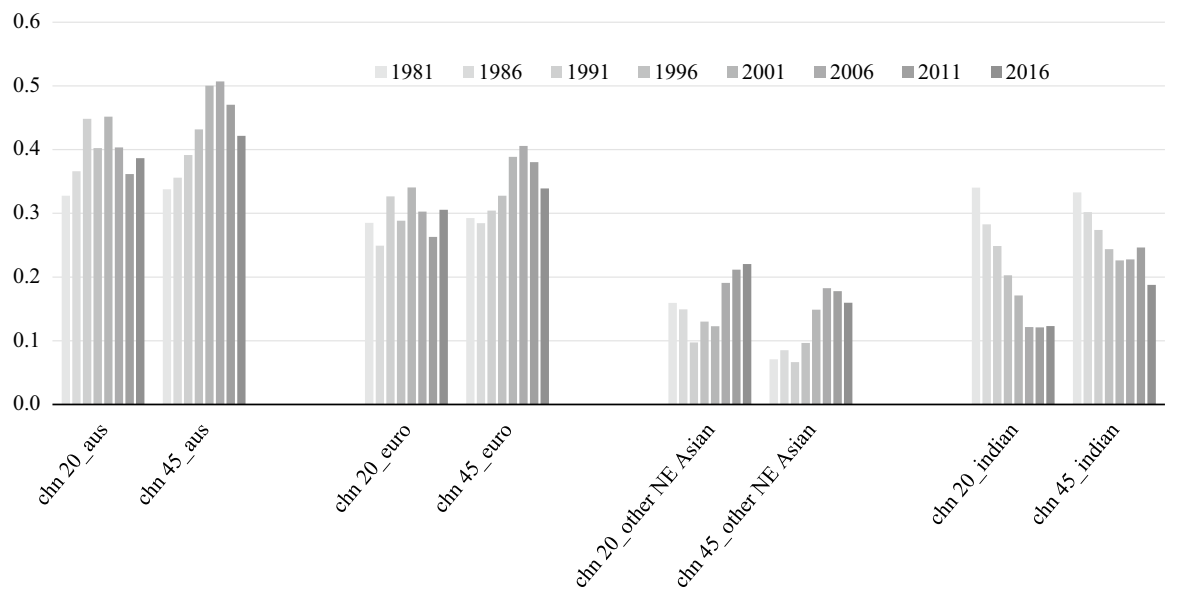

Fig. 6 Index of Dissimilarity between non-Chinese populations and 20-24 years old China-born population (chn_20), between non-Chinese populations and 45-49 years old China-born population (chn_45): HSD level (ABS 1981, 1986, 1991, 1996, 2001a, 2006, 2011a, 2016b). Note: chn: China-born, aus: Australia-born, euro: Europe-born, other NE Asian: non-Chinese North East Asian, ind: India-born

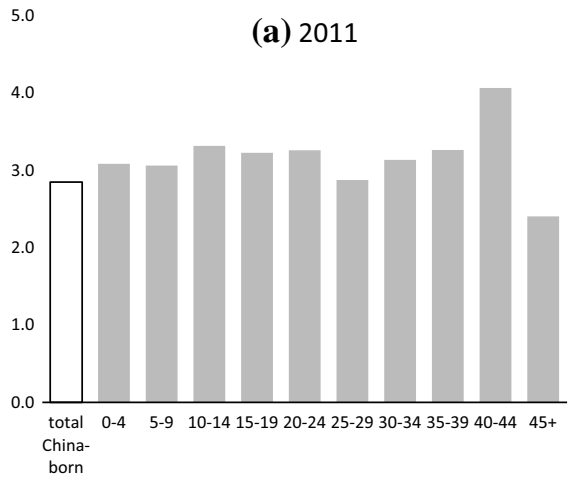

(b.0 2016

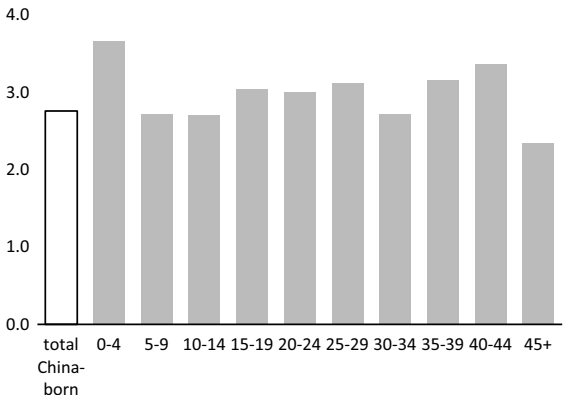

Fig. 72011 and 2016 Coefficient of Variation for different immigrant cohorts (horizontal axis) of the China-born: by the corresponding lengths of residence in Australia, SA2 level (ABS 2011a, 2016b). Note: there are 2193 SA2 areas in 2011 and 2288 SA2 areas in 2016 used in this paper

\section{Across immigrant cohorts}

Presented in Fig. 7, immigrant cohort effects on spatial concentration are measured at SA2 level. The Coefficient of Variation of spatial concentration for the total China-born population is presented as white bars on the left, followed by grey bars on the right representing levels of spatial concentration across immigrant cohorts. Lengths of residence are used to represent immigrant cohorts, with $0-4$ representing those who have been in Australia for less than five years (i.e. those who first arrived in Australia between 2007 and 2011 and recorded in the 2011 Census, or those who 
(a) 2011

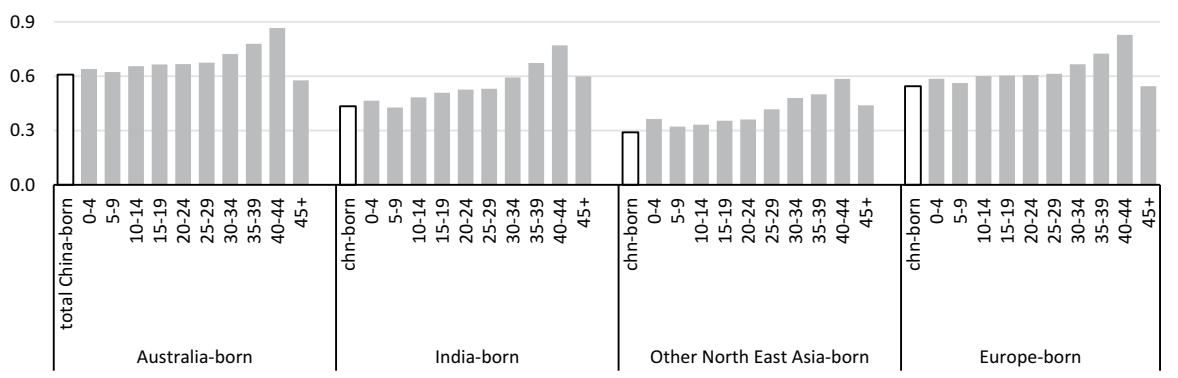

(b) 2016

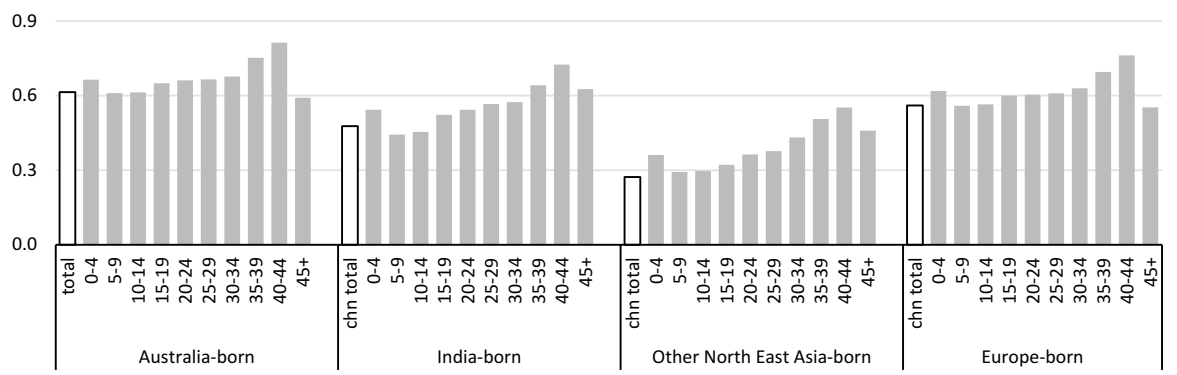

Fig. 8 Index of Dissimilarity between non-Chinese birthplaces and five-year interval China-born immigrant cohorts (denoted using lengths of residence in Australia, horizontal axis): SA2 level, 2011 and 2016 (ABS 2011a, 2016b). Note: there are 2193 SA2 areas in 2011 and 2288 SA2 areas in 2016 used in this paper

arrived between 2012 and 2016 and recorded in the 2016 Census $^{7}$ ) and $45+$ representing those who have been to Australia for 45 and more years (i.e. those who arrived before 1967 and recorded in the 2011 Census, or those who arrived before 1972 and recorded in the 2016 Census). ${ }^{8}$

Comparing the Coefficient of Variation indices across immigrant cohorts in the 2011 Census, those who have lived in Australia for 0-9 years (first arrived in Australia between 2002 and 2011), 25-29 years (first arrived in 1982-1986), and more than 44 years (first arrived before 1967) were relatively less concentrated at the SA2 level. Those who have lived in Australia for 40-44 years (first arrived in 1967-1971) had the highest level of spatial concentration in 2011. Comparing the Coefficient of Variation indices across immigrant cohorts in the 2016 Census, those who have lived in Australia for 5-14 years (first arrived in Australia between 2002 and 2011), 30-34 years (first arrived in 1982-1986), and more than 44 years (first arrived before 1972) showed relatively lower concentration. Those who have lived in Australia for 0-4 years (first arrived in 2012-2016) had the highest level of spatial

\footnotetext{
7 also see Table 1 for a full look-up table.

${ }^{8}$ note this is different from Table 1's earliest arrival group.
} 
concentration in the 2016 Census. This shows that levels of spatial concentration are more relevant to immigrant cohorts rather than lengths of residence for the Chinaborn population in Australia.

The Index of Dissimilarity calculated between the China-born of different lengths of residence in Australia and persons born in Australia, India, other Northeast Asian countries, and European countries at SA2 level are presented in Fig. 8 with data from the 2011 and 2016 Censuses. Levels of spatial evenness between all Chinaborn population and the four non-Chinese populations are presented as white bars on the left side of each sub-figure, followed by grey bars on the right representing levels of spatial evenness between the China-born population of different cohorts and the non-Chinese population (specified on the horizontal axis).

All cohort-specific indices presented in Fig. 8 are higher than or very close to the 0.3 benchmark, showing substantial separations between different China-born immigrant cohorts and the four large Australian populations. Among all immigrant cohorts, those who have been in Australia for 5-9 years and those who have lived in Australia for more than 44 years are relatively less separated from the four nonChinese populations. Conversely, the newest arrivals (with less than five years residence in Australia) were relatively more separated from the four non-Chinese populations. In general, the Index of Dissimilarity gradually increased with the length of residence in Australia increasing, except for the newest and the earliest arrivals. The trend holds true in both 2011 and 2016 Censuses, showing that the duration of residence in Australia has a more significant effect on Chinese spatial integration than the immigrant cohort. This across-duration trend does not agree with findings in spatial assimilation literature where shorter residence at the destination is disadvantaged and is associated with higher segregation (Iceland and Scopilliti 2008; Jones 2003). These patterns may have to do with the characteristics of the newest arrivals, who are predominantly highly educated students or skilled migrants and more 'assimilable' (Portes and Manning 1994).

\section{Conclusion and discussion}

Ever since the dismantlement of discriminatory immigration policies in the mid1970s, multiculturalism and integration of international migrants have been on Australia's policy and research agendas. Among the many facets of integration, spatial integration is of great importance as it is linked to many other aspects of immigrants' integration, particularly their socio-economic integration. This paper uses data from the 1981-2016 Australian Censuses and measures the spatial integration of the China-born population, who became Australia's largest non-European-origin population in the 2000s. With very few exceptions (Coughlan 2008a, b; Edgar 2012; Wang et al. 2018), it remains unclear how spatial integration patterns of the Chinaborn immigrants varied across age groups and immigrant cohorts, on different geographic scales, and over time.

As Richards (2008) puts it: 'there is a spatial preference of coastal cities over regional areas in the Australian population'. The China-born population are also very concentrated in the coastal capital cities, particularly Sydney. However, they became 
less concentrated in Sydney in the post-2001 period, with substantial increases in the numbers of China-born immigrants residing in regional Australia and the other seven capital cities. Additionally, there were more suburbs in the capital city regions that experienced increasing mainland Chinese concentrations. Mapping the distribution of the mainland Chinese population shows a clustering of suburbs with high numbers of mainland Chinese residents in Sydney, Melbourne and Brisbane. Characteristics and compositions of major SA2 settlement areas are consistent with what Wang et al. (2018) found, that the China-born became increasingly concentrated in areas of earlier Chinese settlement or areas with educational resources in Australia's capital cities. Changes in the distribution of China-born immigrants substantiate the 'contrasting' dispersion-concentration picture uncovered in earlier Australian censuses (Coughlan 2008a, b).

With the influx of international students and skilled migrants since the early 2000s, both the Coefficient of Variation and the Index of Dissimilarity show a slow but uninterrupted improvement in the China-born immigrants' spatial integration after the 2001 Australian Census. The improvement is likely driven by the young Chinese and the recent arrivals becoming more integrated. Results from cohort analysis question the duration-integration relationship identified in earlier spatial assimilation literature where immigrant's longer residence in the host country is associated with a lower level of spatial segregation (Jones 2003; Iceland and Scopilliti 2008; Coughlan 2008b). On the other hand, results from this research support findings in Iceland and Scopilliti (2008) where the duration-integration relationship is attributed to characteristics of immigrants such as English language fluency and higher incomes. Post-2001 arrivals from mainland China are predominantly highly educated students or skilled migrants with good English competency. They are possibly more 'assimilable' (Portes and Manning 1994) than earlier Chinese. Considering the newest arrivals being less integrated spatially, it is likely that the interaction between cohort characteristics and lengths of residence in Australia influences the spatial behaviours of mainland Chinese immigrants.

Both initial settlement and subsequent migration of immigrants 'exert a significant effect on the overall distribution of Australia's population' (Bell and Hugo 2000) because 'immigrants have settled in particular parts of the country and ignored others' and that immigrants' subsequent migration patterns have 'differed from the Australia-born population' (p. 128). To understand the process of the China-born population's spatial integration in Australia, future research needs to distinguish international migration from internal migration in contributing to sub-national China-born population growth, using border control data and internal migration statistics.

International migration from China to Australia is historically a significant and rapidly growing flow. This paper develops the understanding of China-born immigrants' spatial integration changes in Australia using eight years of Australian census data. With the cohort and duration effects found in the mainland Chinese population's spatial integration patterns, this paper also contributes to the knowledge of whether and how immigrant cohort and length of residence are linked to spatial concentration and residential unevenness. Understanding these results enriches 
migration integration studies in general, especially in the context of Australia and the context of a broader Chinese diaspora in major immigration countries.

Acknowledgments This research is supported by an Australian Government Research Training Program (RTP) Scholarship. The authors would like to thank James Raymer, Barbara Edgar, the Australian Population Association 2017 Borrie Prize judges, and the two anonymous reviewers for their comments and suggestions on various versions of this paper.

\section{Compliance with ethical standards}

Conflict of interest The authors declare that they have no conflict of interest.

\section{Appendix}

See Map 2 and Tables 3, 4.

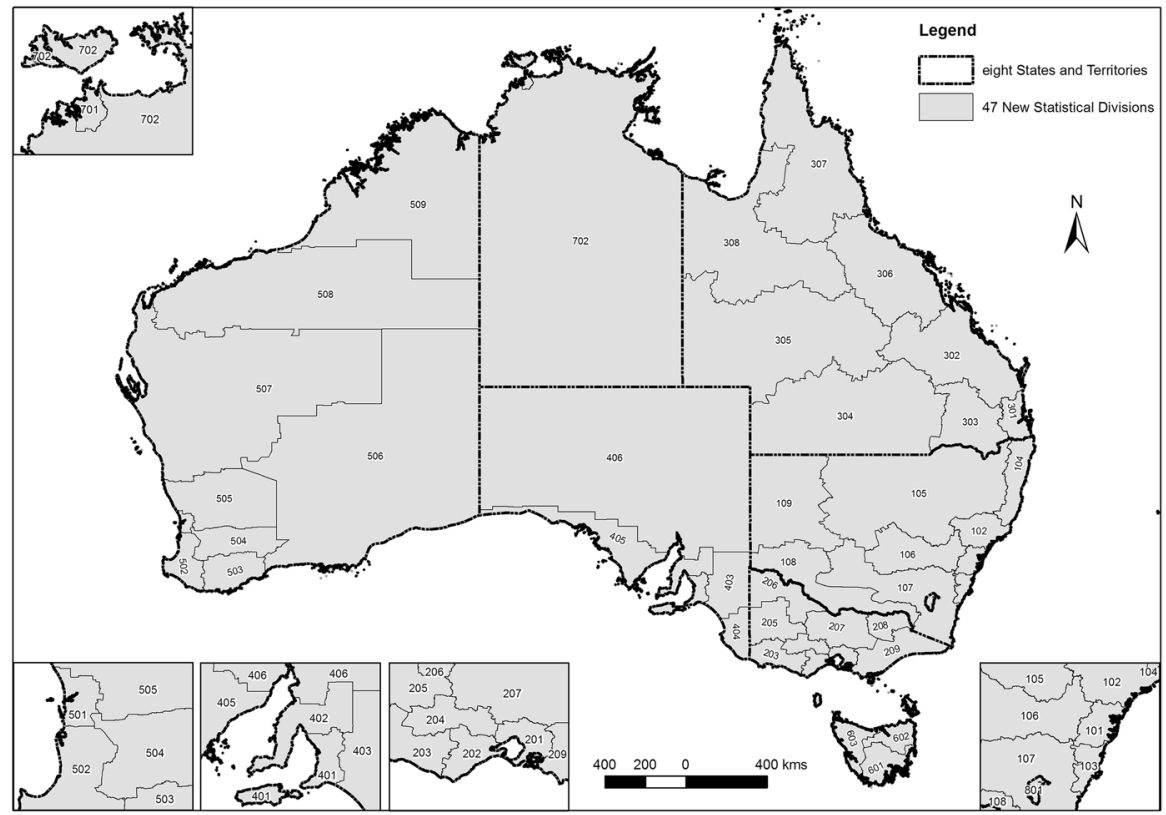

Map 2 Consistent sub-state geography in Australia: 47 Harmonized Statistical Divisions, code numbers 1981-2011 


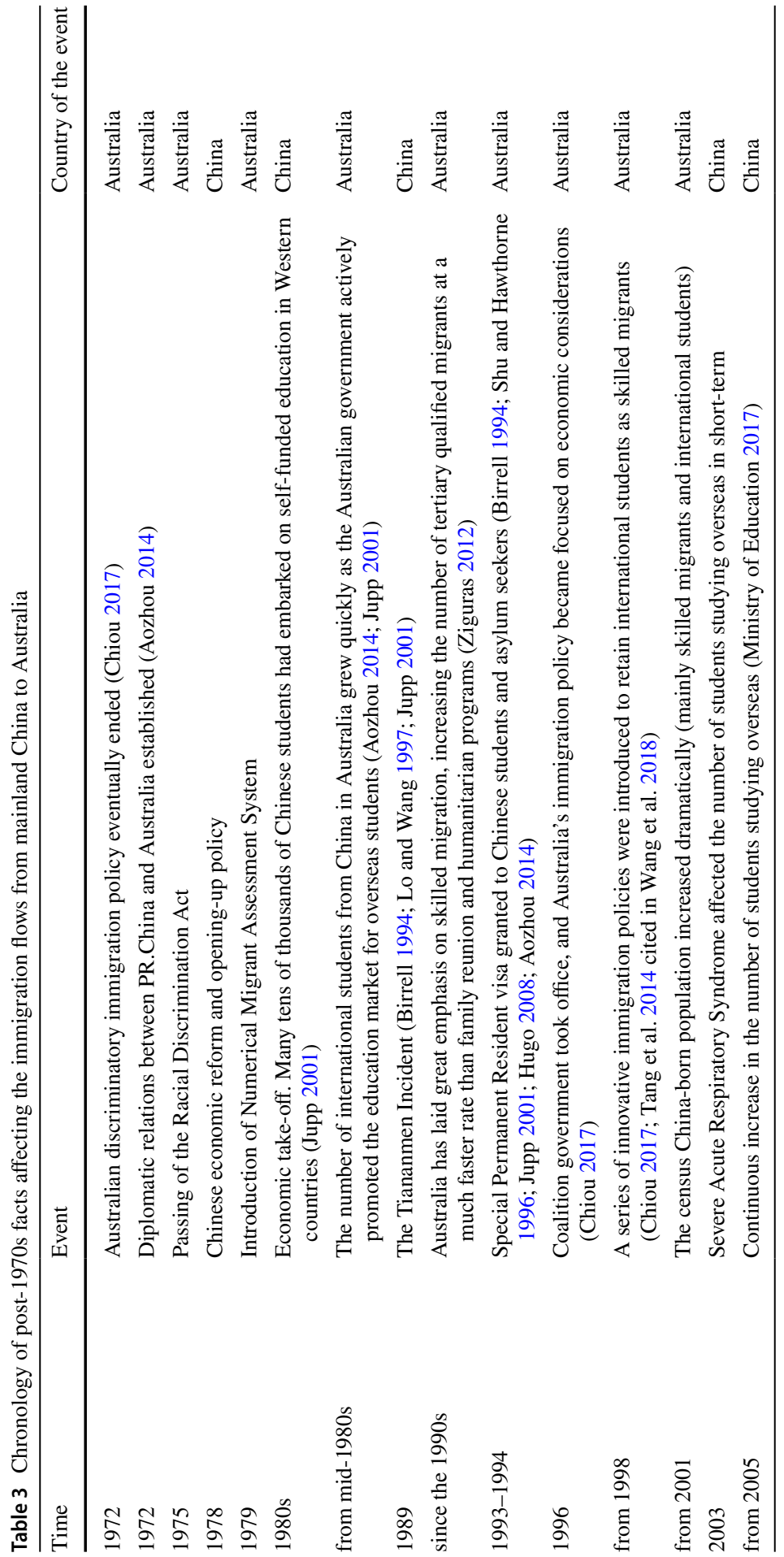


Table 4 Harmonized Statistical Division look up table: code numbers and HSD names

\begin{tabular}{|c|c|c|c|c|c|}
\hline \multirow[t]{2}{*}{ State } & \multicolumn{2}{|c|}{ Harmonized Statistical Division } & \multirow[t]{2}{*}{ State } & \multicolumn{2}{|c|}{ Harnomized Statistical Division } \\
\hline & Code & Names & & Code & Names \\
\hline NSW & 101 & Sydney & QLD & 307 & Far North \\
\hline NSW & 102 & Hunter & QLD & 308 & North West \\
\hline NSW & 103 & Illawarra & SA & 401 & Adelaide/Outer Adelaide \\
\hline NSW & 104 & Richmond-Tweed/Mid-North Coast & SA & 402 & Yorke and Lower North \\
\hline NSW & 105 & Northern/North Western & SA & 403 & Murray Lands \\
\hline NSW & 106 & Central West & SA & 404 & South East \\
\hline NSW & 107 & South Eastern/Murrumbidgee & SA & 405 & Eyre \\
\hline NSW & 108 & Murray & SA & 406 & Northern \\
\hline NSW & 109 & Far West & WA & 501 & Perth \\
\hline VIC & 201 & Melbourne/East Central & WA & 502 & South West \\
\hline VIC & 202 & Barwon & WA & 503 & Lower Great Southern \\
\hline VIC & 203 & Western District & WA & 504 & Upper Great Southern \\
\hline VIC & 204 & Central Highlands & WA & 505 & Midlands \\
\hline VIC & 205 & Wimmera & WA & 506 & South Eastern \\
\hline VIC & 206 & Mallee & WA & 507 & Central \\
\hline VIC & 207 & Loddon/Goulburn & WA & 508 & Pilbara \\
\hline VIC & 208 & Ovens-Murray & WA & 509 & Kimberley \\
\hline VIC & 209 & East Gippsland/Gippsland & TAS & 601 & Greater Hobart/Southern \\
\hline QLD & 301 & Southeast Queensland & TAS & 602 & Northern \\
\hline QLD & 302 & Wide Bay-Burnett/Fitzroy & TAS & 603 & Mersey-Lyell \\
\hline QLD & 303 & Darling Downs & NT & 701 & Darwin \\
\hline QLD & 304 & South West & NT & 702 & Northern Territory - Bal \\
\hline QLD & 305 & Central West & $\mathrm{ACT}$ & 801 & $\mathrm{ACT}$ \\
\hline QLD & 306 & Mackay/Northern & & & \\
\hline
\end{tabular}

\section{References}

ABS. (1981). Australian Population and Housing Census, 1981. Canberra: ABS.

ABS. (1986). Australian Population and Housing Census data, 1986. Canberra: ABS.

ABS. (1991). Australian Population and Housing Census data, 1991. Canberra: ABS.

ABS. (1996). Australian Population and Housing Census data, 1996. Canberra: ABS.

ABS. (2001a). Australian Population and Housing Census data, 2001. Canberra: ABS.

ABS. (2001b). 2001 Census of Population and Housing - Geographic Areas. Canberra: ABS. https:// www.abs.gov.au/websitedbs/D3110124.NSF/f5c7b8fb229cf017ca256973001fecec/53bbe9630b 24d6f4ca256c3a000475b8! OpenDocument. Accessed 1 Feb 2018.

ABS. (2006). Australian Population and Housing Census data, 2006. Canberra: ABS.

ABS. (2010). 1270.0.55.001-Australian Statistical Geography Standard (ASGS): Volume 1-Main Structure and Greater Capital City Statistical Areas, July 2011. Canberra: ABS.

ABS. (2011a). Australian Population and Housing Census data, 2011. Canberra: ABS.

ABS. (2011b). 1216.0 Australian Standard Geographical Classification (ASGC). Canberra: ABS.

ABS. (2016a). 1270.0.55.001 - Australian Statistical Geography Standard (ASGS): Volume 1 - Main Structure and Greater Capital City Statistical Areas. Canberra: ABS.

ABS. (2016b). Australian Population and Housing Census TableBuilder data, 2016. Canberra: ABS. 
Ang, I. (2014). Beyond Chinese groupism: Chinese Australians between assimilation, multiculturalism and diaspora. Ethnic and Racial Studies, 37(7), 1184-1196.

Aozhou Ju Liu Er Shi Zhou Nian Ji Nian Wei Yuan Hui. (2014). Australia: Our extended dreams. Hong Kong: Xianggang Zhongguo Xin Wen Chu Ban She.

Bell, M., Blake, M., Boyle, P., Duke-Williams, O., Rees, P., Stillwell, J., et al. (2002). Cross-national comparison of internal migration: issues and measures. Journal of the Royal Statistical Society, Series A (Statistics in Society), 165(3), 435-464.

Bell, M., \& Hugo, G. (2000). Internal Migration in Australia 1991-1996: Overview and the OverseasBorn. Canberra: Department of Immigration and Multicultural Affairs.

Bell, M., Wilson, T., Charles-Edwards, E., \& Ueffing, P. (2018). Australia: the long-run decline in internal migration intensities. In T. Champion, T. Cooke, \& I. Shuttleworth (Eds.), Internal migration in the developed world: Are we becoming less mobile? (pp. 147-172). Abingdon, United Kingdom: Routledge.

Birrell, B. (1994). Implications of the November 1993 and January 1994 amnesties: How many will be affected and at what cost. People and Place, 2(1), 34-41.

Burnley, I. H. (1992). Enclaves, ghettoes and dispersion? settlement forms in Australian cities in the 1990s. In: I. H. Burnley (Ed.) Immigration: Problems, impacts and futures (pp. 63-73). Sydney: Conference Paper No. 10, Geographical Society of NSW.

Castles, S., Haas, H., \& Miller, M. (2014). The age of migration: International population movements in the modern world (5th ed.). Basingstoke: Palgrave Macmillan.

Chiou, B. (2017). Two-step migration: a comparison of Australia's and New Zealand's policy development between 1998 and 2010. Asian and Pacific Migration Journal, 26(1), 84-107.

Choi, C. Y. (1975). Chinese migration and settlement in Australia. Sydney, Australia: Sydney University Press.

Coughlan, J. E. (2008a). Temporal variations in the spatial distribution of Australia's Chinese communities. Paper presented at the Re-imaging Sociology Conference of The Australian Sociological Association, Melbourne, Australia.

Coughlan, J. E. (2008b). The changing spatial distribution and concentration of Australia's Chinese and Vietnamese communities: An analysis of 1986-2006 Australian population census data. Journal of Population Research, 25(2), 161-182.

Dunn, K. M. (1998). Rethinking Ethnic Concentrations: The case of Cabramatta, Sydney. Urban Studies, 35(3), 503-527.

Edgar B. (2012). Migration concentrations and zones of transition: Ethnic assimilation and pluralism scenarios in Sydney and Melbourne, Australia. Unpublished PhD thesis. Canberra: the Australian National University.

Ewing, W. A. (2012). Opportunity and exclusion: A brief history of U.S. immigration policy. Washington, DC: Immigration Policy Center, American Immigration Council. https://www.americanimmigra tioncouncil.org/sites/default/files/research/opportunity_exclusion_011312.pdf. Accessed 18 Sept 2019.

Guan, Q. (2018). Creating population-based consistent geography over 1981-2011 [unpublished manuscript]. Canberra: School of Demography, Australian National University. http://demography.cass. anu.edu.au/sites/default/files/docs/2018/11/Document_on_Creating_Population-based_Consistent _Geography_over_1981-2011.pdf. Accessed 24 Feb 2018.

Ho, C. H., \& Coughlan, J. E. (1997). The Chinese in Australia: Immigrants from People's Republic of China, Malaysia, Singapore, Taiwan, Hong Kong and Macau. In J. E. Coughlan \& D. J. McNamara (Eds.), Asians in Australia: patterns of migration and settlement (pp. 120-170). South Melbourne, Australia: Macmillan Education Australia.

Huck, A. (1968). The Chinese in Australia. Croydon, Victoria, Australia: Longmans of Australia Pty Limited.

Hugo, G. (2008). A changing diaspora: recent trends in migration between China and Australia. Chinese Southern Diaspora Studies, 2, 82-103.

Hugo, G. (2011). Changing spatial patterns of immigrant settlement. In M. Clyne \& J. Jupp (Eds.), Multiculturalism and integration-A harmonious combination (pp. 1-40). Canberra: ANU E Press.

Hugo, G., \& Harris, K. (2011). Population Distribution Effects of Migration in Australia: Report for Department of Immigration and Citizenship. Adelaide: The University of Adelaide.

Iceland, J., \& Scopilliti, M. (2008). Immigrant residential segregation in US metropolitan areas, 19902000. Demography, 45(1), 79-94.

Inglis, C. (1972). Chinese in Australia. International Migration Review, 6(3), 266-281. 
Johnston, R., Forrest, J., \& Poulsen, M. (2001). The geography of an EthniCity: Residential segregation of birthplace and language groups in Sydney, 1996. Housing Studies, 16(5), 569-594.

Jones, R. C. (2003). The segregation of ancestry groups in San Antonio. The Social Science Journal, 40, 213-232.

Jupp, J. (2001). The Australia people: an encyclopaedia of the nation, its people and their origins. Cambridge: Cambridge University Press.

Kee, P., \& Huck, A. (1991). Immigrant second and third generation Chinese in Australia: a profile drawn from the 1986 census. Asian Studies Review, 14(3), 41-71.

Lichter, D. T., Parisi, D., \& Taquino, M. C. (2015). Toward a new macro-segregation? Decomposing segregation within and between metropolitan cities and suburbs. American Sociological Review, 80(4), 843-873.

Lo, L., \& Wang, S. (1997). Settlement patterns of Toronto's Chinese immigrants: Convergence or divergence? Canadian Journal of Regional Science, 20(12), 49-72.

Massey, D. S., \& Denton, N. A. (1988). The dimensions of residential segregation. Social Forces, 67(2), P281-P315.

Ministry of Education. (2017). Ministry of Education of the People's Republic of China: Education Statistics. Retrieved from http://en.moe.gov.cn/

Musterd, S. (2003). Segregation and integration: a contested relationship. Journal of Ethnic and Migration Studies, 29(4), 623-641.

National Academies of Sciences, Engineering, and Medicine. (2015). The integration of immigrants into American society. Washington, DC: The National Academies Press.

Newman, D. (1985). Integration and ethnic spatial concentration: The changing distribution of the AngloJewish community. Transactions of the Institute of British Geographers, 10(3), 360-376.

Portes and Manning. (1994). The immigrant enclave, theory and empirical examples. In D. B. Grusky (Ed.), Social stratification: class, race, and gender in sociological perspective (pp. 47-68). Boulder, Colorado: Westview Press.

Reardon, S., \& O'Sullivan, D. (2004). Measures of spatial segregation. Sociological Methodology, 34, 121-162.

Reeves, K., \& Mountford, B. (2011). Sojourning and settling: Locating Chinese Australian history. Australian Historical Studies, 42(1), 111-125.

Richards, E. (2008). Destination Australia: Migration to Australia Since 1901. Sydney: UNSW Press.

Rogers, A., \& Raymer, J. (1998). The spatial focus of US interstate migration flows. International Journal of Population Geography, 4, 63-80.

Shu, J., \& Hawthorne, L. (1996). Asian student migration to Australia. International Migration, 34(1), 65-96.

Tang, A. Z. R., Rowe, F., Corcoran, J., \& Sigler, T. (2014). Where are the overseas graduates staying on? Overseas graduate migration and rural attachment in Australia. Applied Geography, 52(9), 66-76.

Wang, S., Sigler, T., Liu, Y., \& Corcoran, J. (2018). Shifting dynamics of Chinese settlement in Australia: And urban geographic perspective. Geographical Research, 56(4), 447-464.

Wessel, T., Andersson, R., Kauppinen, T., \& Andersen, H. S. (2017). Spatial integration of immigrants in Nordic cities: the relevance of spatial assimilation theory in a welfare state context. Urban Affairs Review, 53(5), 812-842.

White, M. J. (1983). The measurement of spatial segregation. American Journal of Sociology, 88(5), 1008-1018.

Wingens, M., Windzio, M., de Valk, H., \& Aybek, C. (Eds.). (2011). A life-course perspective on migration and integration. Dordrecht: Springer.

Winship, C. (1978). The desirability of using the Index of Dissimilarity or any adjustment of it for measuring segregation: reply to Falk, Cortese, and Cohen. Social Forces, 57(2), 717-720.

Ziguras, C. (2012). Learning the hard way, lesson from australia's decade of innovation in student migration policy. In D. E. Neubauer \& K. Kuroda (Eds.), Mobility and migration in Asian Pacific higher education (pp. 39-52). New York: Palgrave Macmillan.

Publisher's Note Springer Nature remains neutral with regard to jurisdictional claims in published maps and institutional affiliations. 